\title{
Performance Analysis of Flat Gain Wideband Raman Amplifier for S+C and C+L Band DWDM System
}

\author{
Dipika D. Pradhan (D) and Abhilash Mandloi \\ Department of Electronics Engineering, Sardar Vallabhbhai National Institute of Technology (SVNIT), Surat, Gujarat, India \\ Correspondence should be addressed to Dipika D. Pradhan; deepika01513@gmail.com
}

Received 5 May 2018; Accepted 14 June 2018; Published 15 August 2018

Academic Editor: Somenath N. Sarkar

Copyright (C) 2018 Dipika D. Pradhan and Abhilash Mandloi. This is an open access article distributed under the Creative Commons Attribution License, which permits unrestricted use, distribution, and reproduction in any medium, provided the original work is properly cited.

\begin{abstract}
Raman amplifier is an open area of research in telecommunication field. This paper discusses the performance of 64 channels of 10 Gbps WDM systems with backward multipump Raman amplifier. The main goal of this paper is the optimization of Raman amplifier to minimize its gain variation without using any gain flattening techniques. To increase the transmission capacity of DWDM system, Raman amplifier with backward multipump configuration is implemented. The optimized parameters such as pump power and frequencies are used to deliver both ground and excited state absorption for amplification in $\mathrm{S}+\mathrm{C}$ and $\mathrm{C}+\mathrm{L}$ band region. The pump power and frequencies are optimized through multitarget and multiparameter optimization tool available in OptiSystem software. Gain ripple was achieved $<0.5 \mathrm{~dB}$ for this simulation setup. The maximum flat gain achieved is $8.6 \mathrm{~dB}$ and noise figure of $<8 \mathrm{~dB}$ was achieved for this wide bandwidth without using gain flattening techniques. This amplifier design will be helpful for CATV applications and telecommunication networks.
\end{abstract}

\section{Introduction}

Optical fiber communication supplies the demand of future communication and achieved low attenuation loss as compared to copper and coaxial cable. In the 1980s, the erbium doped fiber amplifier operated as vital role for the amplification in c band [1]. A single wavelength $1310 \mathrm{~nm}$ is analyzed with different length as a function of wavelength and the amplifier bandwidth is found $14 \mathrm{~nm}-16 \mathrm{~nm}$. It was also compared with $1310 \mathrm{~nm}$ Raman amplifier with SOA resulting in wavelength as $1310 \mathrm{~nm}$ with bandwidth $85 \mathrm{~nm}$ [2]. We demonstrate $\mathrm{C}$ band wavelength Raman amplifier from 1530$1624.4 \mathrm{~nm}$ in this paper. The maximum gain and noise figure achieved for $\mathrm{C}$ band are $53.3 \mathrm{~dB}$ and $9 \mathrm{~dB}$, respectively [3]. In recent years Raman amplifiers are widely used due to wide amplification bandwidth [4]. The paper demonstrated the L band remote pumped EDFA/Raman amplifier using $1480 \mathrm{~nm}$ pump utilizing effect of Raman scattering [5]. The performance analysis of EYDFA and Raman amplifier is analyzed with the help of $110 \times 40 \mathrm{Gbps}$ data rate NRZ format. Different pumping schemes are employed with EYDFA+DFA. It is reported that forward pumping scheme is superior to all other experiments [6]. The gain ripple was $2.09 \mathrm{~dB}$ and OSNR is $34.23 \mathrm{~dB}$ of the work proposed RA with TDM pumps using analytical model. We already reported the performance of hybrid amplifier Raman +EDFA in DWDM system using RZ and NRZ format [7]. Gain flattening filter optimization has been proposed in 320 channels' broadband DWDM system at reduced channel spacing is about $25 \mathrm{GHZ}$ to achieve gain ripple less than $0.5 \mathrm{Db}$ [8]. Optimization tools greatly reduce the design time for required work and fiber Raman amplifier pumped at multiwavelength and frequency reported [9]. Optimization is not done by broad band Raman amplifier [10]. Raman amplifier optimization is done by using particle swarm optimization achieved gain ripple less than $0.5 \mathrm{db}$ [11]. Multiparameter optimization procedure was implemented for the Raman amplifier by particle swarm optimizer [12,13]. The implementation of Raman amplifier based on genetic algorithm can be found in [14]. Multiparameter optimization of Raman amplifier is essential to improve the gain spectrum of Raman amplifier which is not presented in [15-17]. The Raman amplifier can provide the better amplification and gain flattening in $\mathrm{L}$ band to reduce the influence of fiber nonlinearity [18]. The $\mathrm{S}+\mathrm{C}+\mathrm{L}$ band Raman amplifier was 


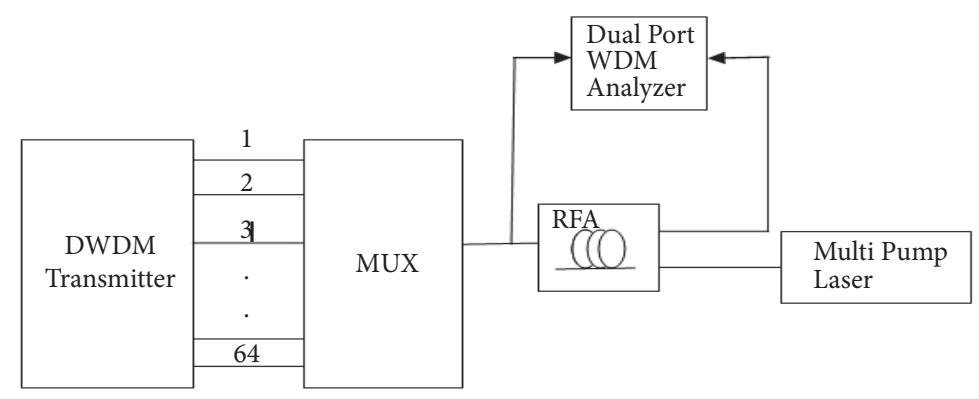

FIGURE 1: Simulation setup of counterpropagation multipump Raman amplifier.

experimented over $100 \mathrm{~nm}$ gain bandwidth of 1520-1620 nm with gain ripple $1.1 \mathrm{~dB}$ [19]. The wideband Raman amplifier over $98 \mathrm{~nm}$ gain bandwidth of 1520-1620 nm has been demonstrated with gain flatness $1 \mathrm{~dB}$ [20]. The flat gain wideband cascaded TDFA and Raman hybrid amplifier is the present requirement of DWDM system [21, 22].

For the first time we have reported reduced gain ripple of $0.2 \mathrm{~dB}$ and $0.5 \mathrm{~dB}$ for $\mathrm{S}+\mathrm{C}$ band and $\mathrm{C}+\mathrm{L}$ band, respectively. This new design of optimum gain flattening performance of Raman amplifier will be useful for telecommunication networks.

The rest of the paper is organized as follows: Section 2 explains simulation setup and analysis of Raman amplifier; Section 3 ends with concluding remarks.

\section{Characteristics of Multipump Raman Amplifier}

The aim behind the optimization of multipump Raman amplifier is to get better gain flatness and reduce ripples instead of utilizing any gain flattening techniques. Gain bandwidth can be improved by Raman amplifier by efficient utilization of DWDM system. In Section 1, we adopted the MPO optimization using OptiSystem simulation software. The optimized four pump powers are utilized to transfer energy from pumps to the signal to provide better gain flatness with less gain variation. MPO tools are available in OptiSystem software to optimize the pump powers and frequencies to achieve the target gain to keep the DWDM system with $0.8 \mathrm{~nm}$ channel spacing. This multipump optimization is based on nonlinear least square (LSQ) algorithm. For the initial stage the four types of pumps are randomly chosen with input power $-17.4 \mathrm{dBm}$ for 64 channels of DWDM system. The MPO is executed with several iterations for the goal attainment of gain flatness to achieve high gain. The signal power was at length $\mathrm{L}$ to amplify the continuous wave signal [23].

$$
\mathrm{P}_{\mathrm{s}}(\mathrm{L})=\mathrm{P}_{\mathrm{s}}(0) \exp \left(\frac{\mathrm{g}_{\mathrm{R}}}{\mathrm{a}_{\mathrm{P}}} \mathrm{P}_{0} \mathrm{~L}_{\text {eff }}-\alpha_{\mathrm{s}} \mathrm{L}\right)
$$

where $\mathrm{L}_{\text {eff }}=\left[1-\exp \left(-\alpha_{P} \mathrm{~L}\right)\right] / \alpha_{\mathrm{P}}$ represent the effective length of the Raman fiber amplifier, where $g_{R}$ represents Raman gain coefficients, $a_{p}$ is the pump cross-sectional area, $\alpha_{\mathrm{s}}$ is the fiber loss, $\mathrm{P}_{0}$ is the input power, and $\mathrm{P}_{\mathrm{s}}(0)$ is the signal power a $\mathrm{L}$

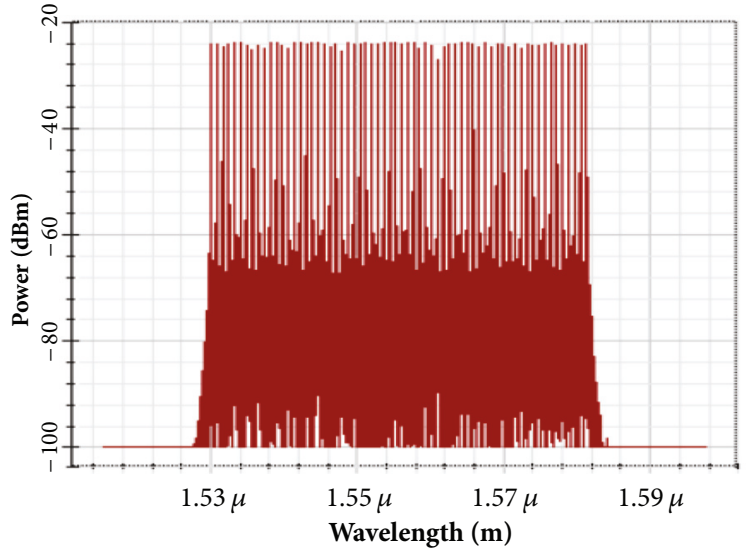

FIGURE 2: Signal of 64-channel WDM system.

$=0$. The basic simulation setup in Figure 1 shows 64 channels where each channel is spaced with $0.8 \mathrm{~nm}$ and output signal power to the Raman amplifier is $-17.4 \mathrm{dBm}$.

DWDM system transmitting several optical channels on to the single fiber is specially designed with non-zerodispersion shifted fiber (NZDSF) which is simulated. NZDSF has the zero-dispersion crossing at wavelengths $<1530 \mathrm{~nm}$ and $>1560 \mathrm{~nm}$. We describe the Raman fiber simulation model in detail that enables the shifting of gain band in both $\mathrm{S}+\mathrm{C}$ band and $\mathrm{C}+\mathrm{L}$ band region. The simulation setup is established in Figure 1 using OptiSystem software. We have investigated the system with $-30 \mathrm{dBm} / \mathrm{channel}$. The simulation setup consists of 64 channels with $10 \mathrm{Gbps}$ data rate/channel in a $100 \mathrm{GHz}(0.8 \mathrm{~nm})$ interval shown in Figure 2. Figure 3 shows the RFA flattened gain has length 25 $\mathrm{km}$ employing four pump lasers operating at pump powers which are $101 \mathrm{~mW}, 136.5 \mathrm{~mW}, 90.1 \mathrm{~mW}$, and $186.07 \mathrm{~mW}$ and frequencies are $1406 \mathrm{~nm}, 1416 \mathrm{~nm}, 1434 \mathrm{~nm}$, and $1461 \mathrm{~nm}$, respectively.

Table 1 summarizes the various simulation parameters applied to the NZDSF fiber. The experiment is carried out with both of $25 \mathrm{~km}$ and $50 \mathrm{~km}$ of fiber length employing optimized pump power and frequencies.

2.1. Results and Discussion. Here NRZ modulation format is used covering bandwidth starting from 1530 to $1581.3 \mathrm{~nm}$ as shown in Figures 4(a) and 4(b) where first channel is 1581.3 


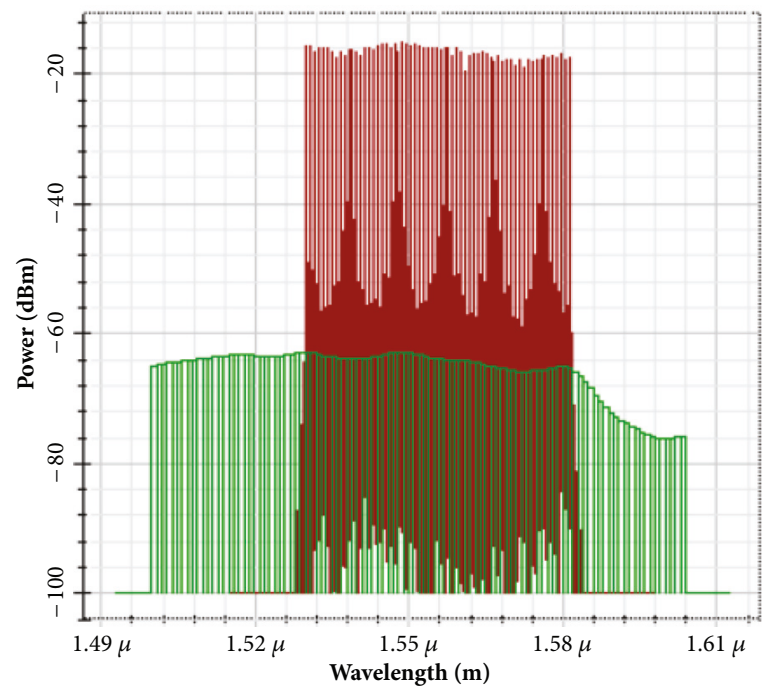

FIgURE 3: Signal of 64-channel WDM system after $25 \mathrm{~km}$ of fiber length.

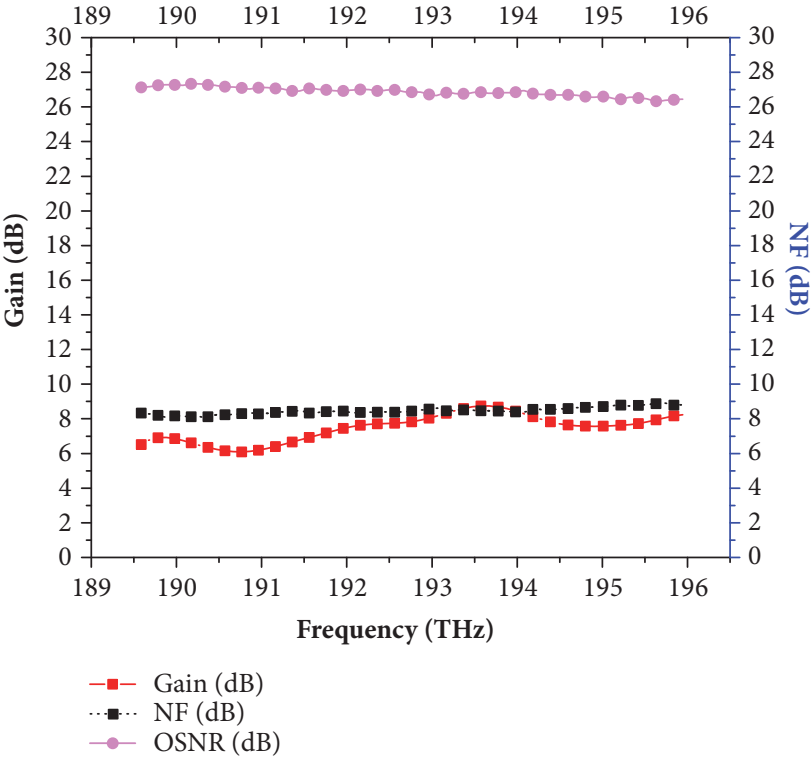

(a)

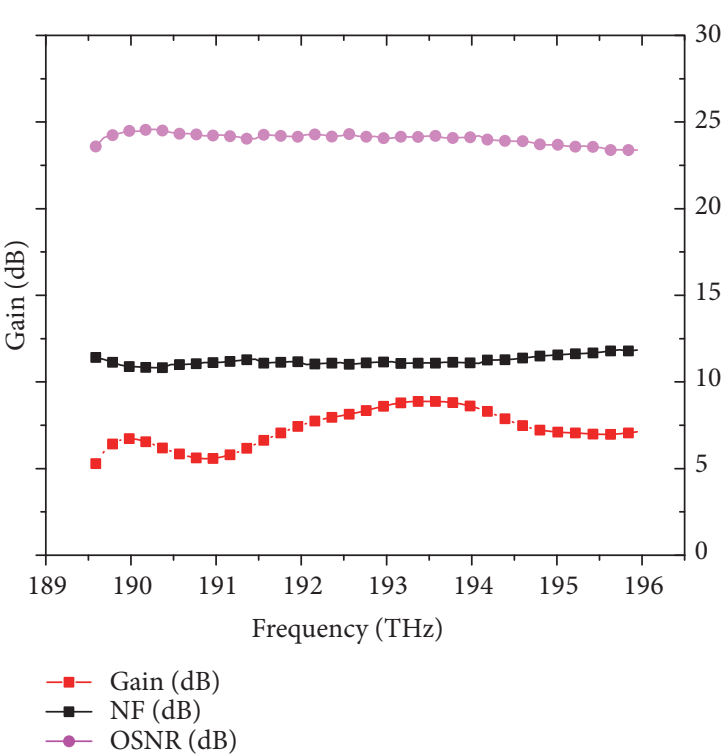

(b)

FIGURE 4: (a) Gain, noise figure, and OSNR versus signal wavelength using counterpropagating pumping scheme at $25 \mathrm{~km}$ length. (b) $50 \mathrm{~km}$ of multipump Raman amplifier in $\mathrm{C}+\mathrm{L}$ band.

TABLE 1: Raman fiber amplifier.

\begin{tabular}{lc}
\hline Parameter & Value \\
\hline Length & $25 \mathrm{~km}, 50 \mathrm{~km}$ \\
Attenuation & $0.2 \mathrm{~dB} / \mathrm{km}$ \\
Dispersion & $16.75 \mathrm{ps} / \mathrm{nm} / \mathrm{km}$ \\
Dispersion Slope & $0.075 \mathrm{ps} / \mathrm{nm} 2 / \mathrm{km}$ \\
Effective Area & $55 \mu \mathrm{m} 2$ \\
Fiber Type & $\mathrm{NZDSF}$ \\
\hline
\end{tabular}

$\mathrm{nm}$ (189 THz), second channel is $1578 \mathrm{~nm}$ (190THz), and last channel is $1530 \mathrm{~nm}(196 \mathrm{THz})$ and also described 1512-1563 $\mathrm{nm}$ as shown in Figures 4(a) and 4(b) where first channel is $1563 \mathrm{~nm}(191 \mathrm{THz})$, second channel is 1561.4 (192 THz), and last channel is $1512 \mathrm{~nm}(198 \mathrm{THz})$.

Figures 4(a) and 4(b) show the values of Raman amplifier for the length of $25 \mathrm{~km}$ and $50 \mathrm{~km}$, respectively. The wavelength range is taken from $1530 \mathrm{~nm}$ to $1581.3 \mathrm{~nm}$ in both cases. The NRZ modulation format is used for both cases. It is evident from Figures 4(a) and 4(b) that bandwidth utilization is $51 \mathrm{~nm}$. The value maximum gain $\mathrm{G}_{\max }$ is taken as $8.7 \mathrm{~dB}$ and minimum gain is taken as $G_{\min } 5.8 \mathrm{~dB}$ and for $25 \mathrm{~km}$ of fiber length. The values of $G_{\max }$ and $G_{\min }$ are taken as $8.7 \mathrm{~dB}$ and $5.2 \mathrm{~dB}$, respectively, for $50 \mathrm{~km}$ of fiber length. The aim of this work is to minimize noise figure (NF) and to maximize OSNR 


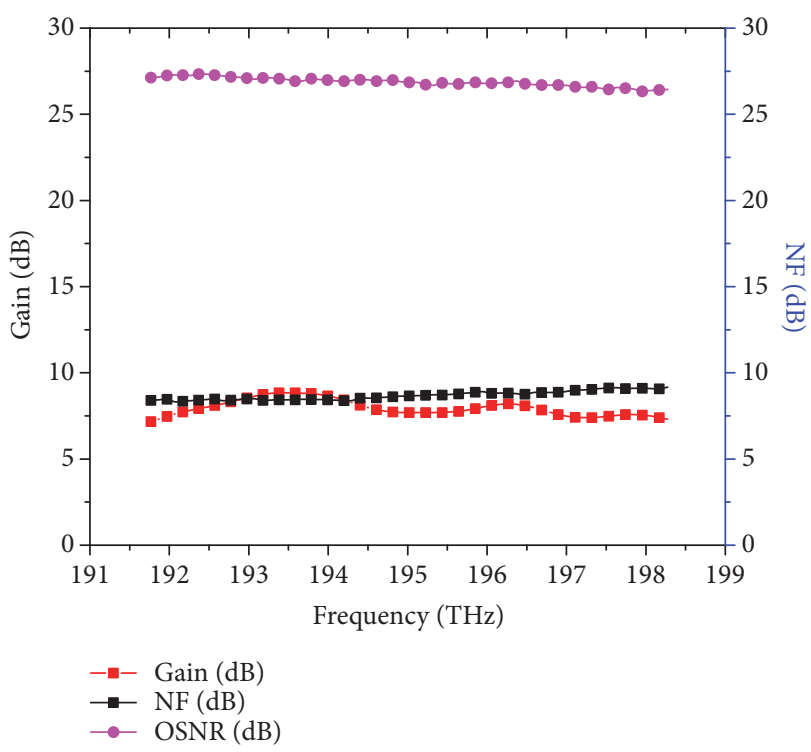

(a)

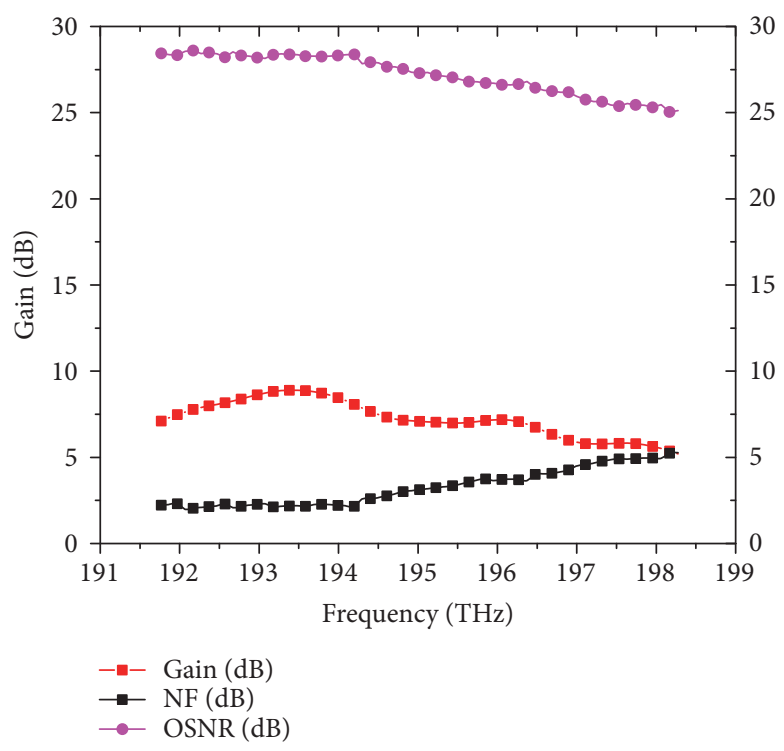

(b)

FIGURE 5: (a) Gain, noise figure, and OSNR versus signal wavelength using counterpropagating pumping scheme at $25 \mathrm{~km}$ length. (b) $50 \mathrm{~km}$ of multipump Raman amplifier in $\mathrm{S}+\mathrm{C}$ band.

to optimize the multipump Raman amplifier. The maximum OSNR, noise figure, and gain for $25 \mathrm{~km}$ fiber length are found to be $29.9 \mathrm{~dB}, 8 \mathrm{~dB}$, and $8.7 \mathrm{~dB}$, respectively. The maximum gain ripple is obtained at $-17.4 \mathrm{dBm}$ for output power of $0.5 \mathrm{~dB}$ and $0.67 \mathrm{~dB}$ for $25 \mathrm{~km}$ and $50 \mathrm{~km}$ of fiber length, respectively. This is evident for $\mathrm{C}+\mathrm{L}$ band as shown in Figures 4(a) and 4(b), respectively. The variations in the power levels are due to the pump signals and do not impart energy to all the channels. From the figures it is clearly observed that a smooth power spectrum is obtained with using any gain flattening filter. The variations of power levels are observed across a wide bandwidth being $1.6 \mathrm{~dB}$ and $2.9 \mathrm{~dB}$ for $\mathrm{S}+\mathrm{C}$ and $\mathrm{C}+\mathrm{L}$ band, respectively.

Figures 5(a) and 5(b) illustrate Raman amplifier for the length of $25 \mathrm{~km}$ and $50 \mathrm{~km}$, respectively, for the wavelength range of 1512-1563 nm with NRZ modulation format. The bandwidth of input channel is taken as $51 \mathrm{~nm}$. The simulation is carried out for $G_{\max }$ of $8.7 \mathrm{~dB}$ and $G_{\min }$ as $7.1 \mathrm{~dB}$, respectively, for $25 \mathrm{~km}$ of fiber length. For $50 \mathrm{kms}$ length $G_{\max }$ and $G_{\min }$ are taken as $8.8 \mathrm{~dB}$ and $5.1 \mathrm{~dB}$, respectively, for 50 $\mathrm{km}$ of fiber length. The maximum OSNR, noise figure, and gain for $25 \mathrm{~km}$ fiber length are found as $29.5 \mathrm{~dB}, 8.3 \mathrm{~dB}$, and $8.7 \mathrm{~dB}$, respectively. The maximum gain ripple is obtained at $-17.4 \mathrm{dBm}$ for output power of $0.2 \mathrm{~dB}$ and $0.7 \mathrm{~dB}$ for $25 \mathrm{~km}$ and $50 \mathrm{~km}$ of fiber length, respectively, in $\mathrm{S}+\mathrm{C}$ band as shown in Figures 5(a) and 5(b).

We have considered NRZ modulation format only for 64 channels' DWDM system. Figure 6 shows the graphical representation of $Q$ value as a function of fiber length varies from $10 \mathrm{~km}$ to $50 \mathrm{~km}$. The maximum quality factor and maximum output power obtained are $13.4 \mathrm{~dB}$ and $5.9 \mathrm{dBm}$, respectively, in $\mathrm{S}+\mathrm{C}$ band DWDM system. Due to the fiber nonlinearities the Q factor decreased. Figure 7 shows the graphical representation of BER as a function of signal

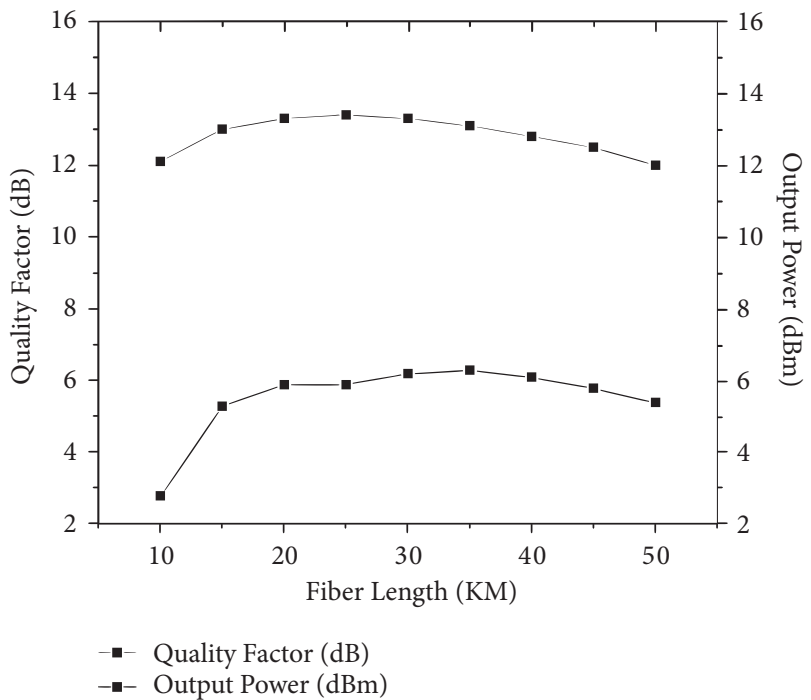

FIGURE 6: Quality factor and output power versus fiber length of multipump Raman amplifier.

wavelength. As shown in the figure the BER is increased as we increase the signal wavelength. The least BER is obtained (1.93453E-39) by NRZ modulation format and for $1600 \mathrm{~nm}$ signal wavelength it becomes $4.53553 \mathrm{E}-5 \mathrm{~dB}$.

Figure 8 illustrates the graphical representation of BER as a function of transmission distance. The length has lowest BER of $2.2 \mathrm{e}^{-31}$ for $25 \mathrm{~km}$ of fiber length and highest BER is obtained about $7.6 \mathrm{e}^{-24}$ for $50 \mathrm{~km}$ of fiber length. Figures 9(d) and 9(i) show the eye diagrams for 64 channels' DWDM system. The intersymbol interference which is introduced due to transmission loss influenced nonlinear effect in the fiber 
TABLE 2: Response of the multipumping Raman fiber amplifier configuration.

\begin{tabular}{lcccc}
\hline $\begin{array}{l}\text { Fiber Configuration } \\
\text { NZDSF }\end{array}$ & Length $=25 \mathrm{~km}$ & C+L Band & \multicolumn{2}{c}{ S+C Band } \\
\hline $\mathrm{G}_{\max }(\mathrm{dB})$ & 8.7 & 8.7 & 8.7 & Length $=25 \mathrm{~km}$ \\
$\mathrm{G}_{\min }(\mathrm{dB})$ & 5.8 & 5.2 & 7.1 & 8.8 \\
Noise Figure $(\mathrm{dB})$ & 8 & 10.8 & 8.3 & 1.1 \\
Gain variation $(\mathrm{dB})$ & 2.9 & 3.5 & 1.6 & 3.6 \\
Gain Ripple $(\mathrm{dB})$ & 0.5 & 0.67 & 0.2 & 0.7 \\
OSNR $(\mathrm{dB})$ & 27.1 & 29.9 & 29.5 & 26.8 \\
\hline
\end{tabular}

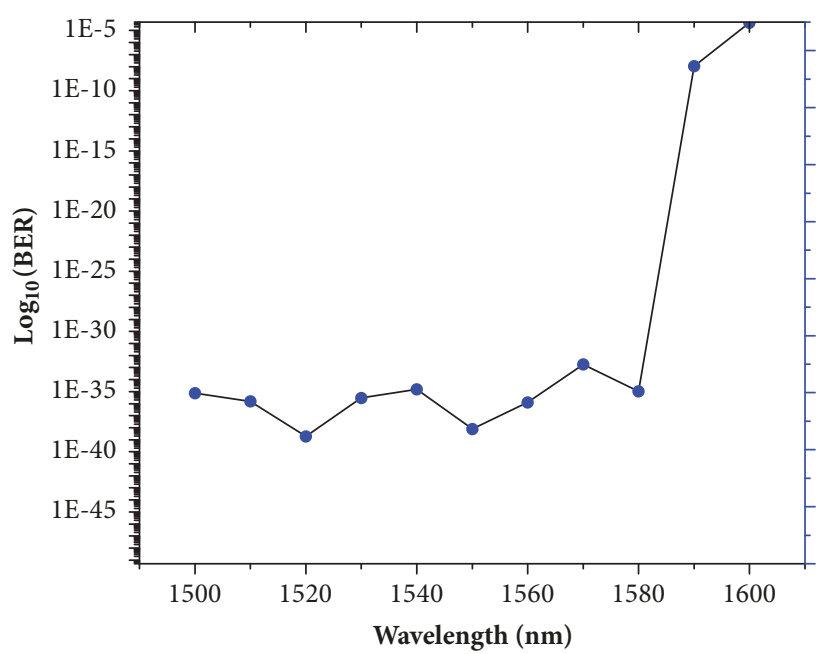

FIGURE 7: BER versus signal wavelength of multipump Raman amplifier.

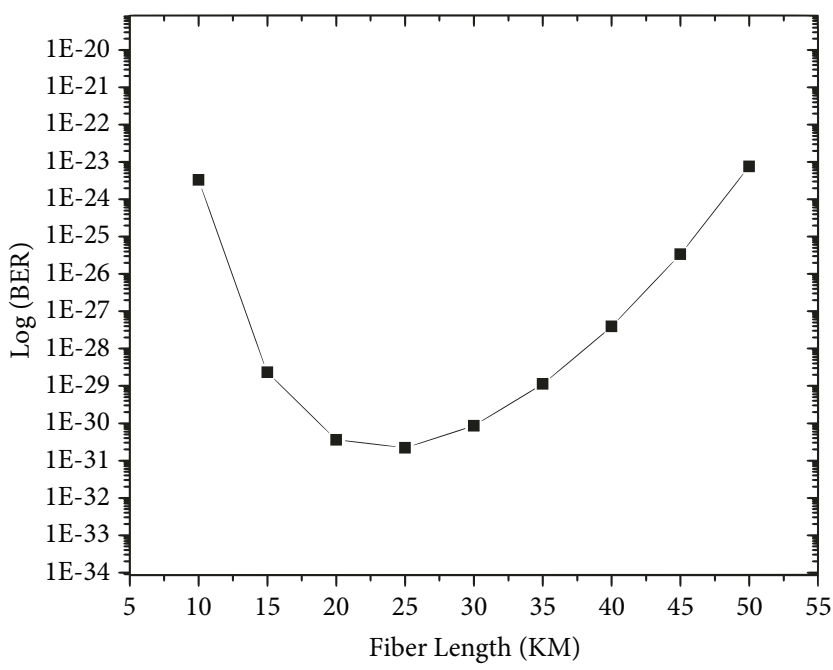

FIGURE 8: BER versus fiber length of multipump Raman amplifier.

due to impulse width being the largest in NRZ modulation format. The eye is more open in case of $25 \mathrm{~km}$ fiber length as compared to all other lengths of fiber with good extinction ratio.

Table 2 shows that Raman amplifier configuration has a ripple of $0.2 \mathrm{~dB}$ and $0.5 \mathrm{~dB}$ for $\mathrm{S}+\mathrm{C}$ band and $\mathrm{C}+\mathrm{L}$ band, respectively. The maximum OSNR is observed at $50 \mathrm{~km}$ of fiber length as compared to $25 \mathrm{~km}$ of fiber length in case of
$\mathrm{C}+\mathrm{L}$ band for $\mathrm{S}+\mathrm{C}$ band the maximum OSNR is at $25 \mathrm{~km}$ of fiber length than $50 \mathrm{~km}$ of fiber length.

\section{Conclusion}

We present cost effective system with only four utilized pumps (see Table 3). This wideband flat gain amplification is implemented by multipump Raman amplifier without 
TABLE 3: Comparison of the proposed investigation with the previous reported system.

\begin{tabular}{|c|c|c|c|c|c|c|}
\hline $\begin{array}{l}\text { Previous } \\
\text { reported System }\end{array}$ & $\begin{array}{c}\text { Operating } \\
\text { band }\end{array}$ & $\begin{array}{c}\text { No. of } \\
\text { Channels }\end{array}$ & $\begin{array}{l}\text { Channel } \\
\text { spacing }\end{array}$ & Gain ripple & $\begin{array}{c}\text { Optimization } \\
\text { of amplifier }\end{array}$ & No. of Pumps \\
\hline $\begin{array}{l}4 \text { backward } \\
\text { pumping } \\
\text { schemes [3] }\end{array}$ & $\mathrm{C}$ band & 45 & $100 \mathrm{GHz}$ & - & No & 4 \\
\hline $\begin{array}{l}160 * 10 \text { Gbps } \\
\text { DWDM system } \\
{[4]}\end{array}$ & $\mathrm{L}$ band & 160 & $25 \mathrm{GHz}$ & $4.5 \mathrm{~dB}$ & No & 2 \\
\hline $\begin{array}{l}8 \text { backward } \\
\text { pumping } \\
\text { scheme }[10]\end{array}$ & $S$ band & 14 & $764.7 \mathrm{GHz}$ & $<0.4 \mathrm{~dB}$ & Yes & 8 \\
\hline $\begin{array}{l}64 * 10 \text { Gbps } \\
\text { and } 96 * 10 \\
\text { Gbps DWDM } \\
\text { system [17] }\end{array}$ & $\mathrm{C}+\mathrm{L}$ band & 96,64 & $100 \mathrm{Ghz}$ & - & No & 1 \\
\hline $\begin{array}{l}320 \text { Channel } \\
\text { DWDM system } \\
\text { [8] }\end{array}$ & $\begin{array}{c}\text { S+C+L band } \\
\text { (With Gain } \\
\text { Flattening } \\
\text { Filter) }\end{array}$ & 320 & $25 \mathrm{Ghz}$ & $<0.5 \mathrm{~dB}$ & Yes & 2 \\
\hline $\begin{array}{l}64 \text { channel } \\
\text { DWDM system }\end{array}$ & $\begin{array}{c}\mathrm{S}+\mathrm{C} \text { and } \mathrm{C}+\mathrm{L} \\
\text { band } \\
\text { (Without } \\
\text { Gain } \\
\text { Flattening } \\
\text { Filter) }\end{array}$ & 64 & $100 \mathrm{GHz}$ & $<0.5 \mathrm{~dB}$ & $\begin{array}{c}\text { Current } \\
\text { Investigation }\end{array}$ & 4 \\
\hline
\end{tabular}

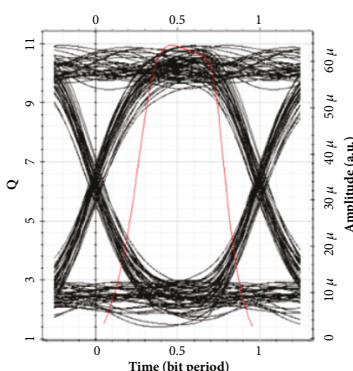

(a)

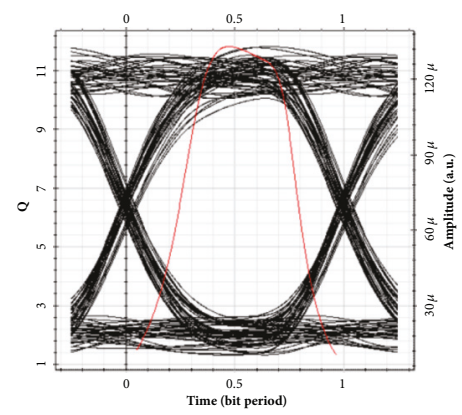

(f)

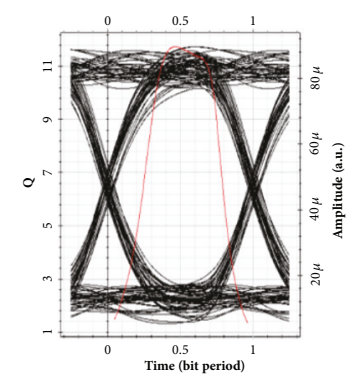

(b)

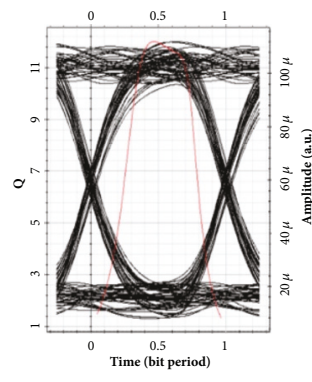

(c)

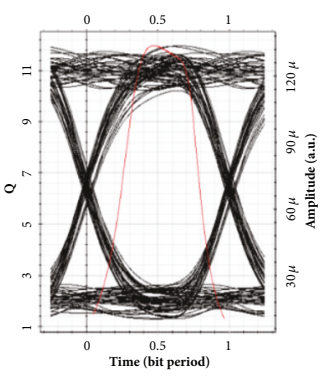

(d)

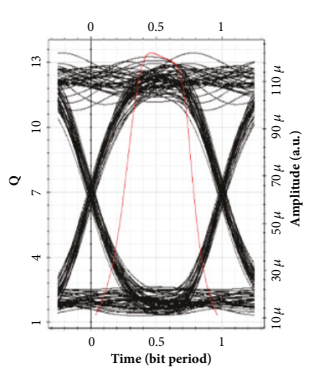

(e)

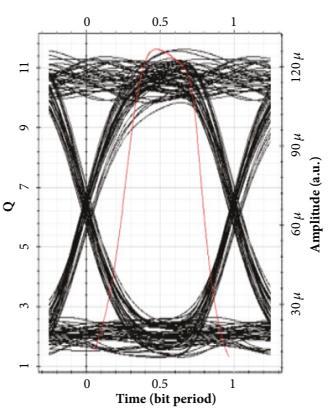

(g)

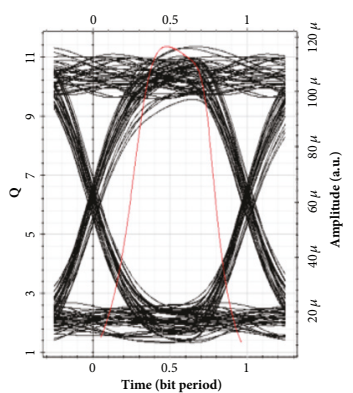

(h)

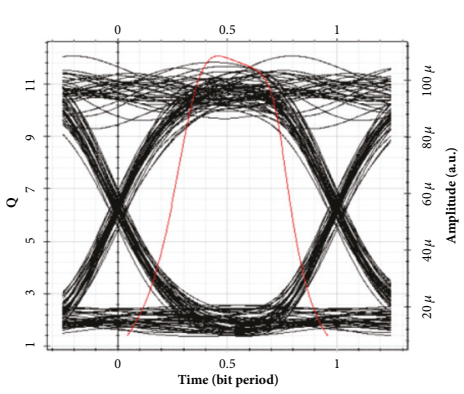

(i)

Figure 9: Eye diagram for 64-channel DWDM system. (a) $10 \mathrm{~km}$ at $10 \mathrm{Gbps}$. (b) $15 \mathrm{~km}$ at $10 \mathrm{Gbps}$. (c) $20 \mathrm{~km}$ at $10 \mathrm{Gbps}$. (d) $25 \mathrm{~km}$ at $10 \mathrm{Gbps}$. (e) $30 \mathrm{~km}$ at $10 \mathrm{Gbps}$. (f) $35 \mathrm{~km}$ at $10 \mathrm{Gbps}$. (g) $40 \mathrm{~km}$ at $10 \mathrm{Gbps}$. (h) $45 \mathrm{~km}$ at $10 \mathrm{Gbps}$. (i) $50 \mathrm{~km}$ at $10 \mathrm{Gbps}$.

using gain flattening filter. The optimized parameters are used for counterpropagating Raman amplifier. The $\mathrm{S}+\mathrm{C}$ band and $\mathrm{C}+\mathrm{L}$ band with $50 \mathrm{~nm}$ wide amplification window cover $1512-1563 \mathrm{~nm}$ and $1530-1580.3 \mathrm{~nm}$. The gain ripple for $\mathrm{S}+\mathrm{C}$ band is found to be $0.2 \mathrm{~dB}$ and $0.7 \mathrm{~dB}$ for 25 $\mathrm{km}$ and $50 \mathrm{~km}$ length of fiber, respectively. The gain ripple for $\mathrm{C}+\mathrm{L}$ band is found to be $0.5 \mathrm{~dB}$ and $0.67 \mathrm{~dB}$ for 25 $\mathrm{km}$ and $50 \mathrm{~km}$ length of fiber, respectively. Better results are observed for $\mathrm{S}+\mathrm{C}$ band than $\mathrm{C}+\mathrm{L}$ bands by Raman amplifier. 


\section{Data Availability}

The data used to support the findings of this study are available from the corresponding author upon request.

\section{Conflicts of Interest}

The authors declare that they have no conflicts of interest.

\section{References}

[1] M. Bass, C. DeCusatis, J. Enoch, V. Lakshminarayan, and G. LiC, "Handbook of optics," in Atmospheric Optics, Modulators, Fiber optics, X-Ray and Neutron optics, vol. 5 of chap. 14, USA, Mc Graw Hill, 2010.

[2] P. Czyzak, P. Mazurek, and J. P. Turkiewicz, "1310 nm Raman amplifier utilizing high-power, quantum-dot pumping lasers," Optics \& Laser Technology, vol. 64, pp. 195-203, 2014.

[3] D. D. Pradhan and A. Mandloi, "Performance Analysis of Backward Multipumped Raman Amplifier in DWDM System," in Proceedings of the 7th International Conference on Advances in Computing and Communications, ICACC '17, pp. 182-187, India, August 2017.

[4] S. Singh and R. S. Kaler, "Flat-gain L-band raman-EDFA hybrid optical amplifier for dense wavelength division multiplexed system," IEEE Photonics Technology Letters, vol. 25, no. 3, pp. 250-252, 2013.

[5] M. H. Abu Bakar, F. R. Mahamd Adikan, N. H. Ibrahim, and M. A. Mahdi, "L-band R-EDFA/Raman hybrid amplifier with enhanced higher-order pumping scheme utilizing stimulated Raman scattering," Optics Communications, vol. 291, pp. 155161, 2013.

[6] H. H. Lee, D. Lee, and H. S. Chung, "A gain-clampedsemiconductor-optical-amplifier combined with a distributed Raman-fiber-amplifier: A good candidate as an inline amplifier for WDM networks," Optics Communications, vol. 229, no. 1-6, pp. 249-252, 2004.

[7] D. D. Pradhan, "Design Optimization of data rate 16x40 Gbps EDFA WDM system," in Proceedings of the International Conference on Fibre Optics and Photonics, p. Tu4A.54, Kharagpur, 2016.

[8] S. Singh, S. Saini, G. Kaur, and R. S. Kaler, "On the Optimization of Raman Fiber Amplifier using Genetic Algorithm in the Scenario of a $64 \mathrm{~nm} 320$ Channels Dense Wavelength Division Multiplexed System," Journal of the Optical Society of Korea, vol. 18, no. 2, pp. 118-123, 2014.

[9] M. Yan, J. Chen, W. Jiang, J. Li, J. Chen, and X. Li, "Automatic design scheme for optical-fiber Raman amplifiers backwardpumped with multiple laser diode pumps," IEEE Photonics Technology Letters, vol. 13, no. 9, pp. 948-950, 2001.

[10] Y. Emori, K. Tanaka, and S. Namiki, "100nm bandwidth flatgain Raman amplifiers pumped and gain-equalised by 12wavelength-channel WDM laser diode unit," IEEE Electronics Letters, vol. 35, no. 16, pp. 1355-1356, 1999.

[11] G. C. M. Ferreira, S. P. N. Cani, M. J. Pontes, and M. E. V. Segatto, "Optimization of distributed Raman amplifiers using a hybrid genetic algorithm with geometric compensation technique," IEEE Photonics Journal, vol. 3, no. 3, pp. 390-399, 2011.

[12] C. J. Bastos-Filho, E. M. Figueiredo, E. A. Barboza et al., "Simple design of Raman fiber amplifiers using a multi-objective optimizer," in Proceedings of the 11th International Conference on
Intelligent Systems Design and Applications (ISDA '11), pp. 11281133, Cordoba, Spain, November 2011.

[13] R. L. Haupt and S. E. Haupt, Practical Genetic Algorithms, John Wiley \& Sons, Hoboken, NJ, USA, 2nd edition, 2004.

[14] J. Zhou and P. Gallion, "Analytical design, analysis, and optimization of raman fiber amplifiers with TDM pumps," IEEE Journal of Quantum Electronics, vol. 46, no. 11, pp. 1597-1604, 2010.

[15] H. M. Jiang, K. Xie, and Y. F. Wang, "Novel design of flat gain spectrum raman fiber amplifiers based on ant colony optimization," IEEE Photonics Technology Letters, vol. 23, no. 23, pp. 1823-1825, 2011.

[16] J. Yasmin and M. K. Atiq, "Optimization of Raman amplifier parameters to achieve flat gain for WDM choatic communication," in Proceedings of the International Conference on Emerging Technologies, ICET '12, pp. 141-144, Pakistan, October 2012.

[17] S. Singh and R. S. Kaler, "Performance evaluation of $64 \times$ 10 Gbps and $96 \times 10$ Gbps DWDM system with hybrid optical amplifier for different modulation formats," Optik International Journal for Light and Electron Optics, vol. 123, no. 24, pp. 2199-2203, 2012.

[18] R. S. Kaler, A. K. Sharma, R. K. Sinha, and T. S. Kamal, "Power penalty analysis for realistic weight functions using differential time delay with higher-order dispersion," Optical Fiber Technology, vol. 8, no. 3, pp. 240-255, 2002.

[19] H. Kidorf, K. Rottwitt, M. Nissov, M. Ma, and E. Rabarijaona, "Pump interactions in a 100-nm bandwidth Raman amplifier," IEEE Photonics Technology Letters, vol. 11, no. 5, pp. 530-532, 1999.

[20] B. Min, W. J. Lee, and N. Park, "Efficient formulation of Raman amplifier propagation equations with average power analysis," IEEE Photonics Technology Letters, vol. 12, no. 11, pp. 1486-1488, 2000.

[21] T. Sakamoto, S.-I. Aozasa, M. Yamada, and M. Shimizu, "Hybrid fiber amplifiers consisting of cascaded TDFA and EDFA for WDM signals," Journal of Lightwave Technology, vol. 24, no. 6, pp. 2287-2295, 2006.

[22] C. Kumar and R. Goyal, "Flattened gain S + C + L Band RAMAN-Thulium-Doped Tellurite Fiber Amplifier Hybrid Optical Amplifier for Super Dense Wavelength Division Multiplexing System," Journal of Optical Communications, 2017.

[23] G. P. Agrawal, Fiber-Optic Communication Systems, John Wiley \& Sons, Inc., Hoboken, NJ, USA, 2010. 


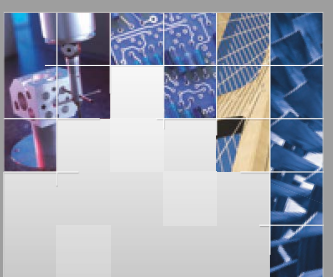

\section{Enfincering}
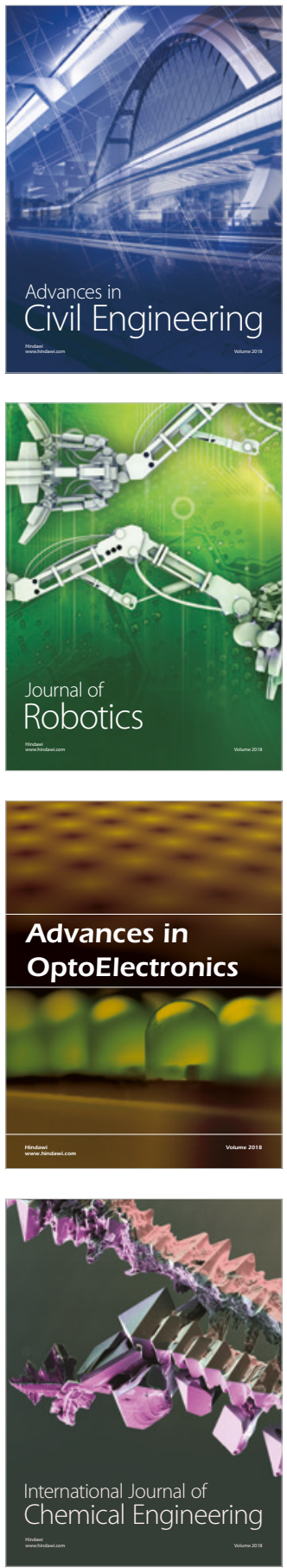

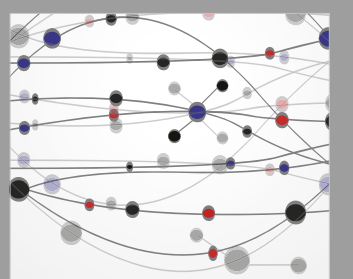

\section{Rotating \\ Machinery}

The Scientific World Journal

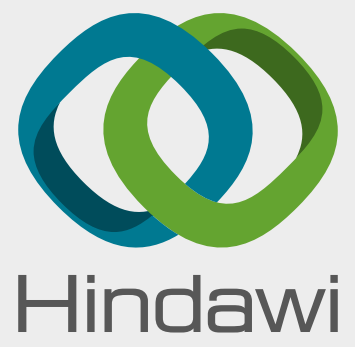

Submit your manuscripts at

www.hindawi.com
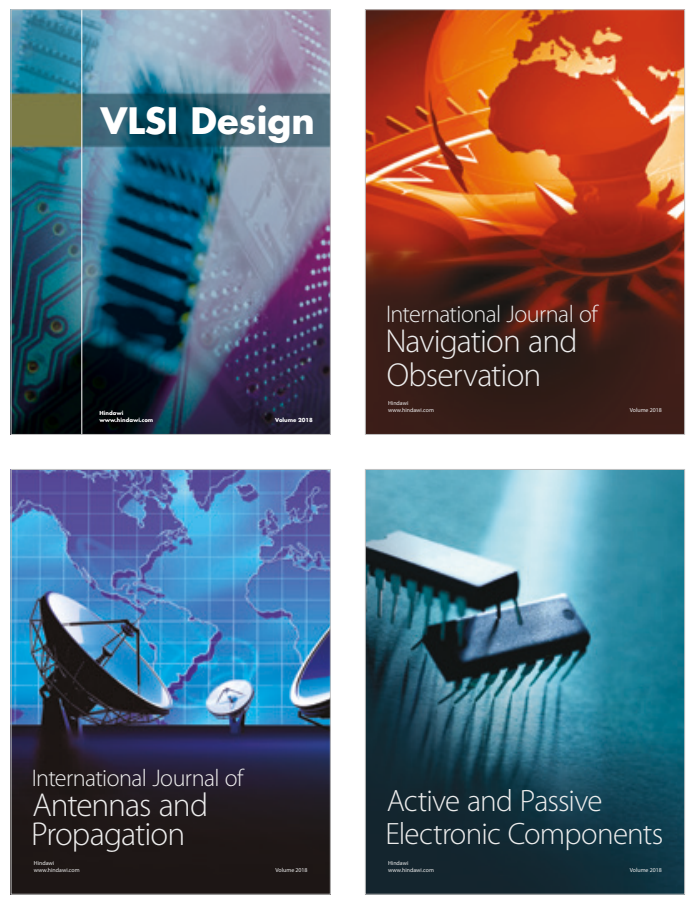
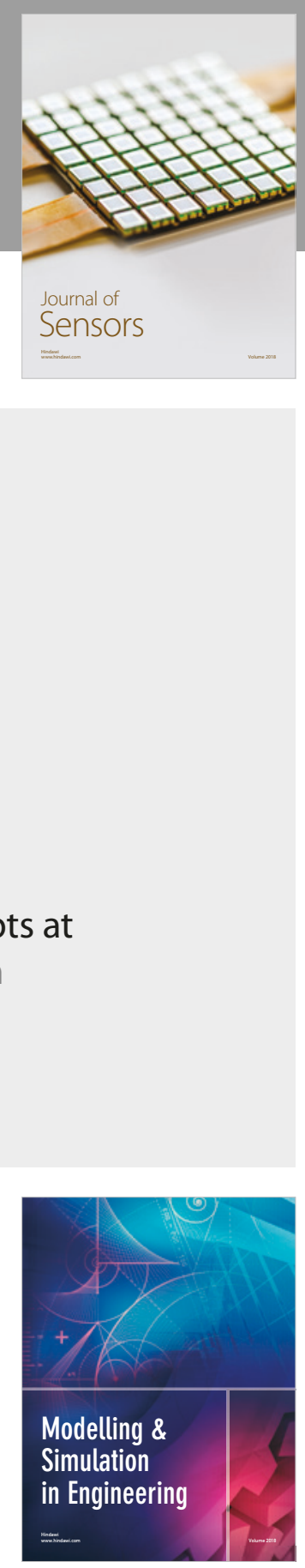

\section{Advances \\ Multimedia}
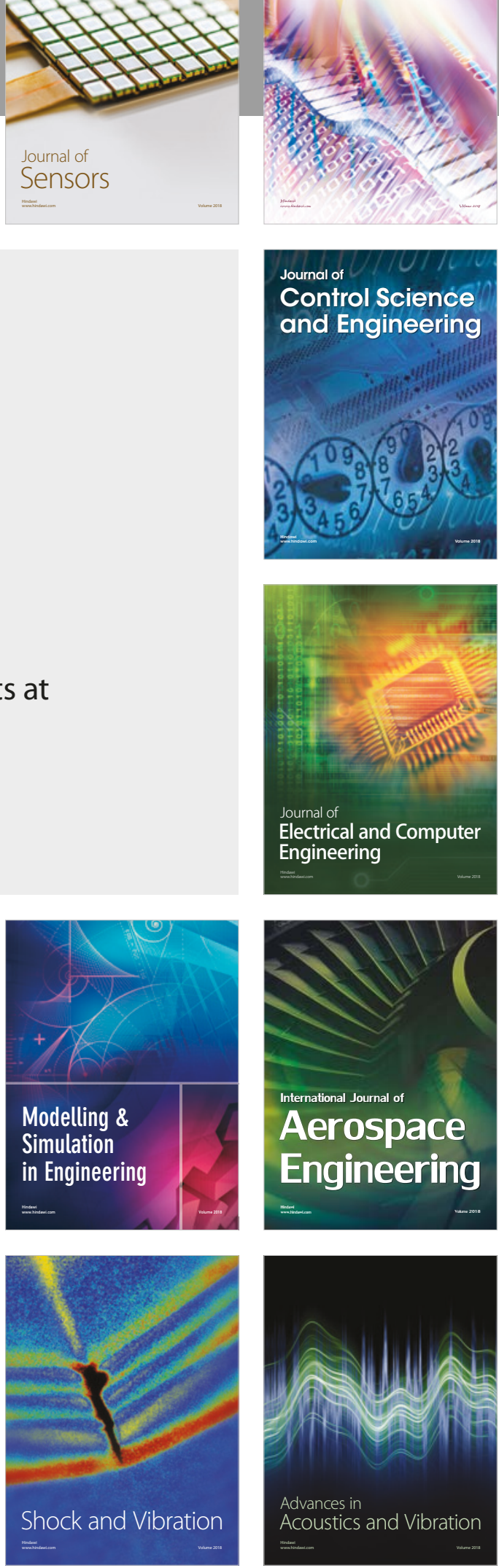